\title{
Use of the modified frailty index to predict 30-day morbidity and mortality from spine surgery
}

\author{
Rushna Ali, MD, ${ }^{1}$ Jason M. Schwalb, MD, ${ }^{1}$ David R. Nerenz, PhD, ${ }^{2}$ Heath J. Antoine, MD, ${ }^{3}$ and \\ llan Rubinfeld, MD, MBA ${ }^{3}$
}

1Department of Neurosurgery, Henry Ford Hospital; ${ }^{2}$ Neuroscience Institute and the Center for Health Policy and Health Services Research, Henry Ford Health System; and ${ }^{3}$ Department of Surgery, Henry Ford Hospital, Detroit, Michigan

OBJECTIVE Limited tools exist to stratify perioperative risk in patients undergoing spinal procedures. The modified frailty index $(\mathrm{mFI})$ based on the Canadian Study of Health and Aging Frailty Index (CSHA-FI), constructed from standard demographic variables, has been applied to various other surgical populations for risk stratification. The authors hypothesized that it would be predictive of postoperative morbidity and mortality in patients undergoing spine surgery.

METHODS The 2006-2010 National Surgical Quality Improvement Program (NSQIP) data set was accessed for patients undergoing spine surgeries based on Current Procedural Terminology (CPT) codes. Sixteen preoperative clinical NSQIP variables were matched to $11 \mathrm{CSHA}-\mathrm{FI}$ variables (changes in daily activities, gastrointestinal problems, respiratory problems, clouding or delirium, hypertension, coronary artery and peripheral vascular disease, congestive heart failure, and so on). The outcomes assessed were 30-day occurrences of adverse events. These were then summarized in groups: any infection, wound-related complication, Clavien IV complications (life-threatening, requiring ICU admission), and mortality.

RESULTS A total of 18,294 patients were identified. In $8.1 \%$ of patients with an $\mathrm{mFI}$ of 0 there was at least one morbid complication, compared with $24.3 \%$ of patients with an $\mathrm{mFI}$ of $\geq 0.27(\mathrm{p}<0.001)$. An $\mathrm{mFI}$ of 0 was associated with a mortality rate of $0.1 \%$, compared with $2.3 \%$ for an $\mathrm{mFI}$ of $\geq 0.27(\mathrm{p}<0.001)$. Patients with an $\mathrm{mFI}$ of 0 had a $1.7 \%$ rate of surgical site infections and a $0.8 \%$ rate of Clavien IV complications, whereas patients with an $\mathrm{mFI}$ of $\geq 0.27$ had rates of $4.1 \%$ and $7.1 \%$ for surgical site infections and Clavien IV complications, respectively ( $p<0.001$ for both). Multivariate analysis showed that the preoperative $\mathrm{mFI}$ and American Society of Anesthesiologists classification of $\geq$ III had a significantly increased risk of leading to Clavien IV complications and death.

CONCLUSIONS A higher mFI was associated with a higher risk of postoperative morbidity and mortality, providing an additional tool to improve perioperative risk stratification.

http://thejns.org/doi/abs/10.3171/2015.10.SPINE14582

KEY WORDS modified frailty index; risk stratification; Clavien IV complications; Canadian Study of Health and Aging Frailty Index; National Surgical Quality Improvement Program

A LTHOUGH surgeons understand and rely on clinical judgment in making decisions regarding an individual patient's ability to tolerate a surgical procedure, such judgment is difficult to quantify and measure in an objective manner. There is a need for adequate tools for objective, preoperative risk stratification, so that patients can be counseled as to what types of complications can be expected and so that different practitioners and health systems can be reasonably and fairly compared. The American Society of Anesthesiologists (ASA) physical status classification has only recently been analyzed as a tool for risk stratification for spine surgery. ${ }^{6} \mathrm{~A}$ formal frailty index used as an independent predictor of postoperative outcomes in patients undergoing spine surgery could prove to be a useful adjunct to the ASA.

Frailty is defined as a decrease in the physiological reserves as well as multisystem impairments that are separate from the normal process of aging. ${ }^{8}$ The concept of frailty denotes progressive physical and mental loss of function and vitality, with or without coexisting disease. The Canadian Study of Health and Aging Frailty Index (CSHA-FI) includes easily identified patient character-

ABBREVIATIONS ACS NSQIP = American College of Surgeons National Surgical Quality Improvement Program; ASA = American Society of Anesthesiologists; CPT = Current Procedural Terminology; CSHA-FI = Canadian Study of Health and Aging Frailty Index; $\mathrm{mFI}=$ modified frailty index.

ACCOMPANYING EDITORIAL See pp 535-536. DOI: 10.3171/2016.1.SPINE151261.

SUBMITTED October 2, 2015. ACCEPTED October 20, 2015.

INCLUDE WHEN CITING Published online May 6, 2016; DOI: 10.3171/2015.10.SPINE14582. 
istics derived from a history and physical examination. Frailty is a known independent factor for postoperative morbidity, mortality, and length of stay, and has also been shown to increase the risk of postoperative delirium, institutionalization, and mortality in cardiac ${ }^{9,10}$ and general surgery patients. ${ }^{11,14,15}$

As has been done in other surgical specialties, ${ }^{4,7,17,19}$ we hypothesized that we could generate a measure of frailty by using data from the American College of Surgeons National Surgical Quality Improvement Program (ACS NSQIP) that would help stratify risk in patients undergoing spine surgery. The ACS NSQIP is the first nationally recognized, risk-adjusted, outcomes-based program to measure and improve the quality of surgical care. The program uses a prospective, peer-controlled, validated database to quantify 30-day risk-adjusted surgical outcomes, which allows comparison of outcomes among all hospitals in the program. For each patient, clinical nurse reviewers record 60 preoperative risk factors, 18 intraoperative factors, and 29 complications, including death, for 30 days postoperatively. Information after discharge is obtained through hospital and clinic medical document review as well as follow-up contact by letter and phone. Patient demographics include sex, race, functional status, and ASA score.

Recent publications have shown that the ACS NSQIP has implemented training and audit procedures for its hospital participants that are highly effective in collecting reliable data. Audit results show that data have been reliable since the program's inception and that reliability has improved every year., ${ }^{3,18}$ The CSHA-FI includes easily identified patient characteristics derived from a history and physical examination. Because the NSQIP database contains similar variables, frailty can be assessed using some of these CSHA-FI variables obtained from NSQIP data for various surgical populations.

In our study, 16 variables in the NSQIP database were matched to 11 corresponding items used in the CSHAFI. These 11 variables were used to calculate the modified frailty index $(\mathrm{mFI})$, a prevalidated risk assessment tool. ${ }^{4,7,11,16,17,19}$ The mFI was created by Tsiouris et al., ${ }^{19}$ who conducted a comparison between the original CSHAFI with variables measured in the NSQIP dataset. Eleven preoperative clinical NSQIP variables were identified that matched some of the original 71 CSHA-FI variables (Table 1). All of the variables were dichotomous (i.e., present or absent). To calculate the $\mathrm{mFI}$, the presence of each variable equals 1 point, and the total points for each patient were divided by 11 to obtain the patient's $\mathrm{mFI}$ score (range $0-1.0)^{4,7,14,17,19,21}$ An increase in the mFI score implies increased frailty.

Thus, with the aid of this prevalidated risk assessment tool, we sought to determine whether the mFI was predictive of postoperative morbidity and mortality in a national sample of patients undergoing spine surgery.

\section{Methods}

The 2006-2010 ACS NSQIP data sets were used to identify the neurosurgical population undergoing spinal surgeries based on Current Procedural Terminology (CPT) codes and surgeon specialty. This was done under
TABLE 1. List of 11 variables used by the CSHA to construct the $\mathrm{mFI}$

\begin{tabular}{l}
\hline \multicolumn{1}{c}{ Variables } \\
\hline Non-independent functional status \\
\hline History of diabetes mellitus \\
\hline History of chronic obstructive pulmonary disease \\
\hline History of congestive heart failure \\
\hline History of myocardial infarction \\
\hline History of percutaneous coronary intervention, cardiac surgery, or \\
angina \\
\hline Hypertension requiring the use of medication \\
\hline Peripheral vascular disease or rest pain \\
\hline Impaired sensorium \\
\hline Transient ischemic attack or cerebrovascular accident w/o residual \\
deficit
\end{tabular}

the data user agreement of the ACS and with the approval of our institutional review board.

The occurrence of postoperative complications as well as 30-day mortality was analyzed in comparison with the $\mathrm{mFI}$ score. The postoperative complications analyzed were the 30-day rates of wound infection (defined as surgical site infection, including superficial, deep, and organ space infections); any infection (defined as wound infection, urinary tract infection, or pneumonia); Clavien IV complications (life-threatening complications requiring ICU admission as depicted in Table 2); and mortality. Clavien IV complications include pulmonary embolism, renal failure, failure to wean patient off ventilator, and stroke. Univariate analysis of the effect of the mFI score on each of the end points was performed. Chi-square analysis and

\section{TABLE 2. Clavien classification of surgical complications*}

\begin{tabular}{cc}
\hline Grade & Definition \\
\hline I & $\begin{array}{c}\text { Any deviation from the normal postoperative course w/o the } \\
\text { need for pharmacological treatment or surgical, endoscop- } \\
\text { ic, \& radiological interventions } \\
\text { Allowed therapeutic regimens are: drugs such as antiemetics, } \\
\text { antipyretics, analgetics, diuretics, electrolytes, \& physio- } \\
\text { therapy. This grade also includes wound infections opened } \\
\text { at the bedside }\end{array}$ \\
\hline II & $\begin{array}{c}\text { Requiring pharmacological treatment w/ drugs other than } \\
\text { those allowed for Grade I complications }\end{array}$ \\
& $\begin{array}{c}\text { Blood transfusions \& total parenteral nutrition are also } \\
\text { included }\end{array}$ \\
\hline III $\quad \begin{array}{c}\text { Postoperative complications requiring radiological, endo- } \\
\text { scopic, or surgical interventions }\end{array}$ \\
\hline IV $\quad \begin{array}{c}\text { Life-threatening complications requiring ICU management, \&/ } \\
\text { or single-organ dysfunction, \&/or multiorgan dysfunction }\end{array}$ \\
\hline V $\quad$ Complications leading to death
\end{tabular}

* Modified with permission from Wolters Kluwer Health from Dindo D, Demartines N, Clavien PA. Classification of surgical complications: a new proposal with evaluation in a cohort of 6336 patients and results of a survey. Ann Surg 240:205-213, 2004. 


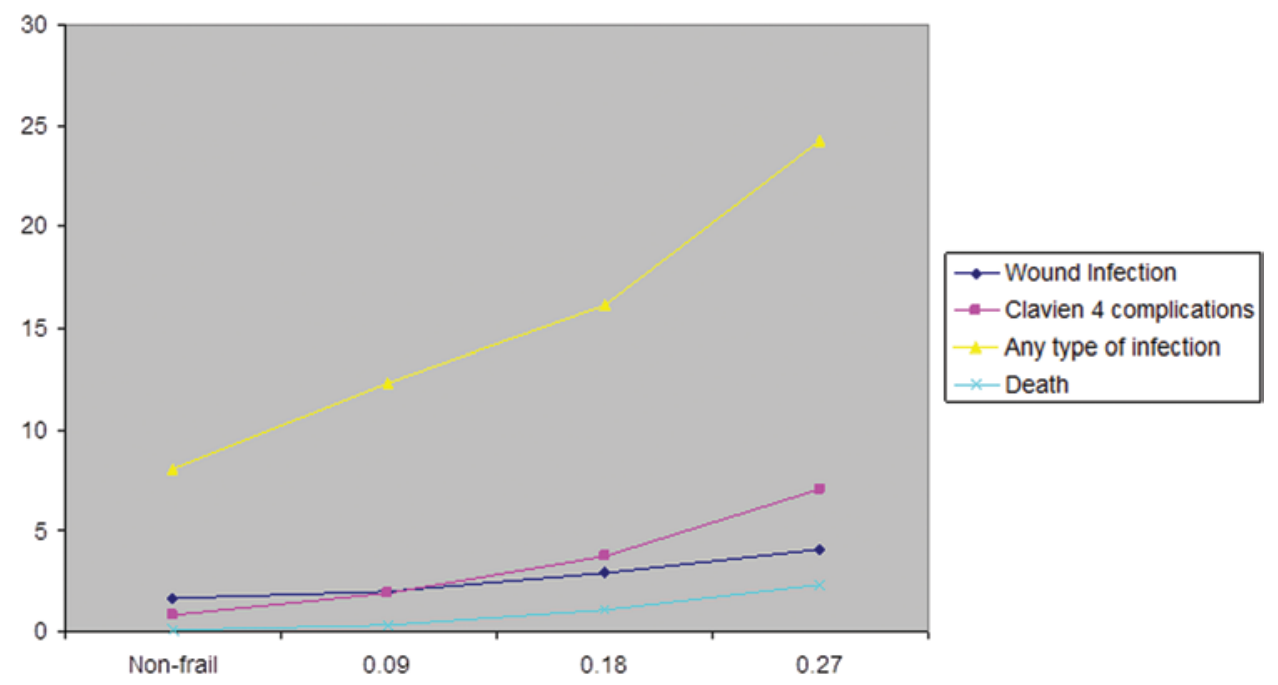

FIG. 1. Dose-response relationship between the $\mathrm{mFI}$ and rate of complications. The values on the $y$ axis denote number of days postsurgery, and the values on the $x$ axis represent the frailty index. Figure is available in color online only.

nominal logistic regression were performed in SPSS 20 (IBM Corp.).

For the purpose of analysis, any $\mathrm{mFI}$ score of $\geq 0.27$ was classified into one category and was considered significantly frail. This cutoff of 0.27 was selected based on prior published work on the $\mathrm{mFI} .{ }^{4,7,11,19} \mathrm{We}$ also performed sensitivity analyses using other cutoff point scores in the mFI to define frailty (Fig. 1 and Table 3).

\section{Results}

Of 18,294 patients who had spine surgery during the time period studied, $90.4 \%$ were white and $8.3 \%$ were African American; the remaining patients were classified as "other." Forty-eight percent were female and 51.7\% were male. The most common ASA class was II, which accounted for $51.7 \%(\mathrm{n}=9461)$ of the patients; followed by ASA Class III, which accounted for $38.0 \%(\mathrm{n}=6967)$ of the patients. The most common spinal procedures performed are listed in Table 4.

Eight percent of patients with an $\mathrm{mFI}$ of 0 had at least 1 infection, compared with $24.3 \%$ patients with an $\mathrm{mFI}$ of $\geq 0.27$ ( $p<0.001)$. An mFI of 0 was associated with a mortality rate of $0.1 \%$, compared with $2.3 \%$ for an mFI of $\geq 0.27$ ( $\mathrm{p}<0.001)$. Surgical site infections and Clavien IV complications occurred in $1.7 \%$ and $0.8 \%$, respectively, of patients with an mFI of 0 , compared with $4.1 \%$ and $7.1 \%$,

TABLE 3. Dose-response relationship between $\mathrm{mFI}$ and rate of complications in 18,294 patients

\begin{tabular}{lccrrrr}
\hline & \multicolumn{4}{c}{$\begin{array}{c}\text { Relationship Btwn mFI \& } \\
\text { Rate of Complications }\end{array}$} & \\
\cline { 2 - 6 } Complications & Non-Frail & 0.09 & 0.18 & $\geq 0.27$ & p Value \\
\hline Wound infection & 1.7 & 2 & 2.9 & 4.1 & $<0.001$ \\
\hline Clavien Grade IV & 0.8 & 1.9 & 3.7 & 7.1 & $<0.001$ \\
\hline Any type of infection & 8.1 & 12.3 & 16.1 & 24.3 & $<0.001$ \\
\hline Death & 0.1 & 0.3 & 1.1 & 2.3 & $<0.001$ \\
\hline
\end{tabular}

respectively, in patients with an $\mathrm{mFI}$ of $\geq 0.27$ ( $\mathrm{p}<0.001$ for both).

Nominal logistic regression showed that preoperative $\mathrm{mFI}$ and an ASA classification of $\geq$ III are independently associated with significantly increased risk of Clavien IV complications (Tables 3 and 5, Figs. 1 and 2). A higher mFI score had a greater (although not statistically significantly greater) odds ratio than a higher ASA class in predicting Clavien IV complications.

The sensitivity analysis involving alternative cutoff points for the mFI is illustrated in Table 3 and Fig. 1. Alternative cutoff points of 0.09 and 0.18 also identify patients at higher risk of postsurgical complications; the higher the cutoff point, the greater the difference between patients with that level of frailty and patients with an $\mathrm{mFI}$ of 0 in the likelihood of postsurgical complications.

\section{Discussion}

Several earlier studies have attempted to provide a risk score for patients undergoing spine surgery. However, most have focused on individual risk factors and surgery subtypes that contribute to greater morbidity and mortality. ${ }^{1,2,5,12,13,22}$ One group evaluated a Surgical Apgar Score, based on intraoperative heart rate, blood loss, and blood pressure, as a predictor of 30-day morbidity and mortality,

TABLE 4. List of the most common spinal procedures per CPT codes in 18,294 patients

\begin{tabular}{lcc}
\hline \multicolumn{1}{c}{ Procedure } & Frequency & $\%$ \\
\hline Lumbar laminectomy \& discectomy & 6718 & 36.7 \\
\hline Lumbar fusion & 1297 & 7.0 \\
\hline Anterior cervical decompression & 776 & 4.2 \\
\hline Anterior cervical fusion & 834 & 4.5 \\
\hline Cervical $360^{\circ}$ fusion & 1064 & 5.8 \\
\hline Cervical laminectomy \& fusion & 170 & 0.9 \\
\hline Thoracic decompression \& fusion & 238 & 0.1 \\
\hline
\end{tabular}


TABLE 5. Dose-response relationship between ASA class and rate of complications in 18,279 patients

\begin{tabular}{lccc}
\hline & \multicolumn{2}{c}{$\begin{array}{c}\text { Relationship Btwn ASA Class } \\
\text { \& Rate of Complications }\end{array}$} & \\
\cline { 2 - 3 } Complications & ASA I \& II & ASA III-V & p Value \\
\hline Clavien Grade IV & 0.48 & 1.29 & $<0.001$ \\
\hline Death & 0.06 & 0.43 & $<0.001$ \\
\hline
\end{tabular}

but it was not found to be a strong predictor. ${ }^{20}$ The ASA classification has proven to be a reliable predictor of 30day postoperative morbidity and mortality in spine surgery. ${ }^{6}$ However, this study was from the Scoliosis Research Society, and so there was a high rate of instrumentation (70\%-80\% of cases) and greater complexity than in most practices. The NSQIP is more weighted toward lowercomplexity cases in spine surgery because such data are mostly collected at hospitals that do not have high enough volumes in general and vascular surgery alone to meet their minimum case volumes. Our analysis does not reflect the highly complex spinal procedures performed at a few specialized centers, but instead reflects the more routine spine surgeries commonly performed on a national level.

Our analysis is the first to demonstrate the utility of the ASA classification in predicting complications in spine surgeries of lower complexity (Table 4), with a significant weighting toward lumbar discectomy. In addition, we found that assessment of frailty is an independent predictor of morbidity and mortality, as shown by multivariate logistic regression. Figures 1 and 2 show the linearity of the prediction. We elected to use 0.27 as the cutoff point of frailty as a compromise. A higher cutoff point would have included moderately to severely frail patients only. As a result we would have reached a greater statistical significance, but the results may have been less clinically relevant, since elective spine surgery is generally not offered to individuals in such poor health. Lower cutoff points would have led to less significant results due to the combination of moderately and severely frail patients with mildly frail patients. Several prior studies in different surgical disciplines have used the same cutoff point for similar reasons. ${ }^{4,7,17,19}$

A frailty index has been demonstrated to predict postoperative outcomes in general surgery patients. ${ }^{11} \mathrm{~A}$ frailty measure developed by Makary et al. composed of 5 aspects (weakness, weight loss, exhaustion, low physical activity, and decreased speed of walking) was applied to patients age $\geq 65$ years who underwent elective surgery over a 1-year period. The investigators' results indicated that preoperative frailty was an independent predictor of postoperative complications, increased length of stay, and discharge to a skilled nursing or assisted-living facility. ${ }^{11}$ The effect of frailty on outcomes has been assessed by multivariate regression analysis adjusted for ASA class in several studies. ${ }^{4,711,19}$ Frailty retained the highest odds ratio for both Clavien IV and V complications in multivariate analysis compared with ASA class. ${ }^{4,711,19}$ To our knowledge, no studies have investigated frailty as a predictor of surgical outcome in patients undergoing spine surgery.

In our study, we elected to use an $\mathrm{mFI}$ based on the CSHA-FI and the data available on NSQIP. Although we

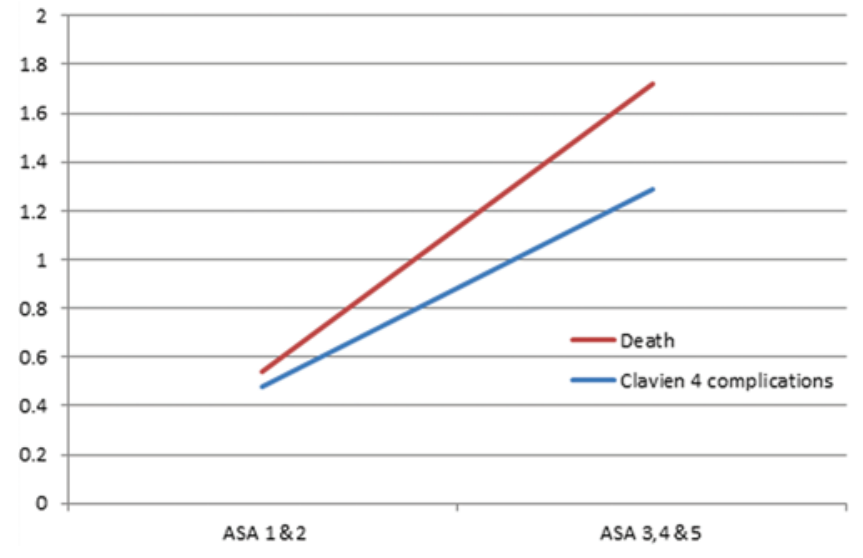

FIG. 2. Dose-response relationship between ASA class and rate of complications. The values on the y axis denote odds ratios. Figure is available in color online only.

did not use the entire original index, prior studies have shown that a satisfactory risk assessment can be made using fewer patient variables and is adequate in generating a satisfactory risk assessment. ${ }^{16,17}$ It has been reported that when using the CSHA-FI, a combination of any 10 items from the index resulted in a similar predictive value for the calculated frailty score. ${ }^{16}$ Pairing the original 70 -item CSHA-FI to an 11-item $\mathrm{mFI}$ is more practical and requires less time to obtain the data and perform the analysis. All of these elements are collected in a routine review of systems. In addition, the variables evaluated in the $\mathrm{mFI}$ do not require physicians to conduct objective measurements but instead to use trained abstractors called surgical clinical reviewers (SCRs) for this purpose. This helps avoid issues with test-retest variability and interrater reliability.

We demonstrated in this study that the mFI score is an independent predictor of postoperative morbidity and mortality from spine surgery in this population. Although this study does not demonstrate superiority or inferiority of the $\mathrm{mFI}$ relative to the ASA in this population, we demonstrated a trend toward a greater odds ratio of developing a severe complication with $\mathrm{mFI}$ - with a cutoff of 0.27 -than with ASA. Given these results, the mFI appears to be a valuable predictive tool, adding to our clinical armamentarium of preoperative risk assessment. We are confident that this will allow the surgeon to make decisions regarding patient selection more effectively and will assist in preoperative counseling of both patients and their families.

We recognize that the retrospective nature of our study can be considered a weakness. Future studies should focus on prospective validation and analysis of the mFI. In addition, it is likely that the predictive value of the $\mathrm{mFI}$ will vary based on the complexity of the different procedures. A subset analysis will certainly prove helpful for further delineation, because the morbidity of different spine surgeries is heavily dependent on the disease process, the number of levels operated on, and the usage of hardware.

\section{Conclusions}

The mFI can successfully predict the postoperative morbidity and mortality for patients undergoing spine sur- 
gery. It is based on easily identifiable preoperative variables that can be gathered on a standard preoperative visit and do not require the involvement of trained physicians. It is a useful tool for risk stratification and serves as an objective measure to help describe potential risks of spine surgery to patients and their families.

\section{Acknowledgments}

We acknowledge Manpreet Kaur, MS, for her help with designing the tables and graphs. The ACS NSQIP and the hospitals participating in the ACS NSQIP are the source of the data used herein; they have not verified and are not responsible for the statistical validity of the data analysis or the conclusions derived by the authors.

\section{References}

1. Atlas SJ, Keller RB, Wu YA, Deyo RA, Singer DE: Longterm outcomes of surgical and nonsurgical management of lumbar spinal stenosis: 8 to 10 year results from the Maine Lumbar Spine Study. Spine (Phila Pa 1976) 30:936-943, 2005

2. Chaichana KL, Pendleton C, Sciubba DM, Wolinsky J-P, Gokaslan ZL: Outcome following decompressive surgery for different histological types of metastatic tumors causing epidural spinal cord compression. Clinical article. J Neurosurg Spine 11:56-63, 2009

3. Davis CL, Pierce JR, Henderson W, Spencer CD, Tyler C, Langberg R, et al: Assessment of the reliability of data collected for the Department of Veterans Affairs national surgical quality improvement program. J Am Coll Surg 204:550-560, 2007

4. Farhat JS, Velanovich V, Falvo AJ, Horst HM, Swartz A, Patton JH Jr, et al: Are the frail destined to fail? Frailty index as predictor of surgical morbidity and mortality in the elderly. $\mathbf{J}$ Trauma Acute Care Surg 72:1526-1531, 2012

5. Fineberg SJ, Oglesby M, Patel AA, Singh K: Incidence and mortality of perioperative cardiac events in cervical spine surgery. Spine (Phila Pa 1976) 38:1268-1274, 2013

6. Fu KMG, Smith JS, Polly DW Jr, Ames CP, Berven SH, Perra JH, et al: Correlation of higher preoperative American Society of Anesthesiology grade and increased morbidity and mortality rates in patients undergoing spine surgery. $\mathbf{J}$ Neurosurg Spine 14:470-474, 2011

7. Karam J, Tsiouris A, Shepard A, Velanovich V, Rubinfeld I: Simplified frailty index to predict adverse outcomes and mortality in vascular surgery patients. Ann Vasc Surg 27:904-908, 2013

8. Kulminski AM, Ukraintseva SV, Kulminskaya IV, Arbeev KG, Land K, Yashin AI: Cumulative deficits better characterize susceptibility to death in elderly people than phenotypic frailty: lessons from the Cardiovascular Health Study. J Am Geriatr Soc 56:898-903, 2008

9. Lee DH, Buth KJ, Martin B-J, Yip AM, Hirsch GM: Frail patients are at increased risk for mortality and prolonged institutional care after cardiac surgery. Circulation 121:973978, 2010

10. Leung JM, Tsai TL, Sands LP: Brief report: preoperative frailty in older surgical patients is associated with early postoperative delirium. Anesth Analg 112:1199-1201, 2011

11. Makary MA, Segev DL, Pronovost PJ, Syin D, BandeenRoche K, Patel P, et al: Frailty as a predictor of surgical outcomes in older patients. J Am Coll Surg 210:901-908, 2010

12. Martin BI, Mirza SK, Franklin GM, Lurie JD, MacKenzie TA, Deyo RA: Hospital and surgeon variation in complications and repeat surgery following incident lumbar fusion for common degenerative diagnoses. Health Serv Res 48:1-25, 2013

13. Ma Y, Passias P, Gaber-Baylis LK, Girardi FP, Memtsoudis SG: Comparative in-hospital morbidity and mortality after revision versus primary thoracic and lumbar spine fusion. Spine J 10:881-889, 2010

14. Obeid NM, Azuh O, Reddy S, Webb S, Reickert C, Velanovich V, et al: Predictors of critical care-related complications in colectomy patients using the National Surgical Quality Improvement Program: exploring frailty and aggressive laparoscopic approaches. J Trauma Acute Care Surg 72:878883,2012

15. Robinson TN, Eiseman B, Wallace JI, Church SD, McFann KK, Pfister SM, et al: Redefining geriatric preoperative assessment using frailty, disability and co-morbidity. Ann Surg 250:449-455, 2009

16. Rockwood K, Andrew M, Mitnitski A: A comparison of two approaches to measuring frailty in elderly people. J Gerontol A Biol Sci Med Sci 62:738-743, 2007

17. Rubinfeld I, Farooq M, Velanovich V, Syed Z: Predicting surgical risk: how much data is enough? AMIA Annu Symp Proc 2010:777-781, 2010

18. Shiloach M, Frencher SK Jr, Steeger JE, Rowell KS, Bartzokis $\mathrm{K}$, Tomeh MG, et al: Toward robust information: data quality and inter-rater reliability in the American College of Surgeons National Surgical Quality Improvement Program. J Am Coll Surg 210:6-16, 2010

19. Tsiouris A, Hammoud ZT, Velanovich V, Hodari A, Borgi J, Rubinfeld I: A modified frailty index to assess morbidity and mortality after lobectomy. J Surg Res 183:40-46, 2013

20. Urrutia J, Valdes M, Zamora T, Canessa V, Briceno J: Can the Surgical Apgar Score predict morbidity and mortality in general orthopaedic surgery? Int Orthop 36:2571-2576, 2012

21. Velanovich V, Antoine H, Swartz A, Peters D, Rubinfeld I: Accumulating deficits model of frailty and postoperative mortality and morbidity: its application to a national database. J Surg Res 183:104-110, 2013

22. Wang MC, Chan L, Maiman DJ, Kreuter W, Deyo RA: Complications and mortality associated with cervical spine surgery for degenerative disease in the United States. Spine (Phila Pa 1976) 32:342-347, 2007

\section{Disclosures}

The authors report no conflict of interest concerning the materials or methods used in this study or the findings specified in this paper.

\section{Author Contributions}

Conception and design: Schwalb, Rubinfeld. Acquisition of data: Antoine, Rubinfeld. Analysis and interpretation of data: Ali, Schwalb, Nerenz, Antoine, Rubinfeld. Drafting the article: Ali, Nerenz. Critically revising the article: Ali, Schwalb, Nerenz, Rubinfeld. Reviewed submitted version of manuscript: Ali, Schwalb, Nerenz, Rubinfeld. Statistical analysis: Rubinfeld. Administrative/technical/material support: Antoine.

\section{Supplemental Information \\ Previous Presentations}

Portions of this work were presented in poster form at the Congress of Neurological Surgeons annual meeting, held in Chicago, IL, on October 6-10, 2012.

\section{Correspondence}

Rushna Ali, Department of Neurosurgery, Henry Ford Hospital, 2799 West Grand Blvd., Detroit, MI 48202. email: rali1@hfhs. org. 